\title{
PRELIMINARY NOTES ON THE DISTRIBUTION OF AIDANOSAGITTA DELICATA (TOKIOKA) IN TANABE BAY
}

\section{$\operatorname{AUTHOR}(\mathrm{S}):$}

Fukuma, Toshihide; Shimizu, Koji

\section{CITATION:}

Fukuma, Toshihide ... [et al]. PRELIMINARY NOTES ON THE DISTRIBUTION OF

AIDANOSAGITTA DELICATA (TOKIOKA) IN TANABE BAY. PUBLICATIONS OF THE SETO MARINE BIOLOGICAL LABORATORY 1966, 14(3): 171-175

\section{ISSUE DATE:}

1966-07-20

URL:

http://hdl.handle.net/2433/175441

RIGHT: 


\title{
PRELIMINARY NOTES ON THE DISTRIBUTION OF AIDANOSAGITTA DELICATA (TOKIOKA) IN TANABE BAY ${ }^{1)}$
}

\author{
Toshinide FUKUMA and KoJi SHIMIZU
}

Zoological Institute, Kyoto University

With 3 Text-figures

As to the distribution and the population dynamics of the Japanese inlet water chaetognaths in respective localities, observations have been made on Aidanosagitta crassa (TOKIOKA) by KAdo (1953-57) and especially in detail by Murakami (195759), but no significant data are available as to the other species, A. delicata (TokiokA), excepting a brief note on the population of this species in Ago Bay (TokiokA, 1951). It is stated only that $A$. delicata occurs commonly and densely in some bays on the coasts of Kyûsyû and Honsyû Islands affected markedly by the Kurosio. This small and delicate arrow worm occurs commonly in Tanabe Bay, too. While we were engaging in the regular marine biology course at the Seto Marine Biological Laboratory in July 1965, we had a chance to make nine hauls of a plankton net at six stations in the bay (Fig. 1) and to examine the collected chaetognaths. The results of our examination seem to show some clear trends prevailing in the distribution of this arrow worm in this bay, though they are not sufficient to afford any final conclusion.

In three days July 24 to 26 , a KrTAHARA's standard quantitative plankton net stretched with the gauze with $0.2 \mathrm{~mm}$ meshes was hauled vertically from $10 \mathrm{~m}$ to the surface and a colsing net of a similar structure was hauled at some stations from $20 \mathrm{~m}$ to $10 \mathrm{~m}$. Six hauls were made on July 24 and other three respectively in successive days. Examination of samples was first made under binocula $r$ microscope, and measurement of specimens was made on a large slide glass with $1 \mathrm{~mm} \times 1 \mathrm{~mm}$ grid. The results are given in Table 1 and Fig. 2, and some hydrological data at respective stations, which were obtained by other students during the same biology course, are shown in Table 2 and Fig. 3.

The data given in Table 1 and Fig. 2 show evidently the following two tendencies: (1). A. delicata occurs abundantly in coves of the bay, but decreases sharply in the open bay proper. (2). At deep stations in cove, smaller individuals are

1) Contributions from the Seto Marine Biological Laboratory, No. 455.

Publ. Seto Mar. Biol. Lab., Vol. XIV (3), 171-175, $1966 . \quad$ (Article 13) 


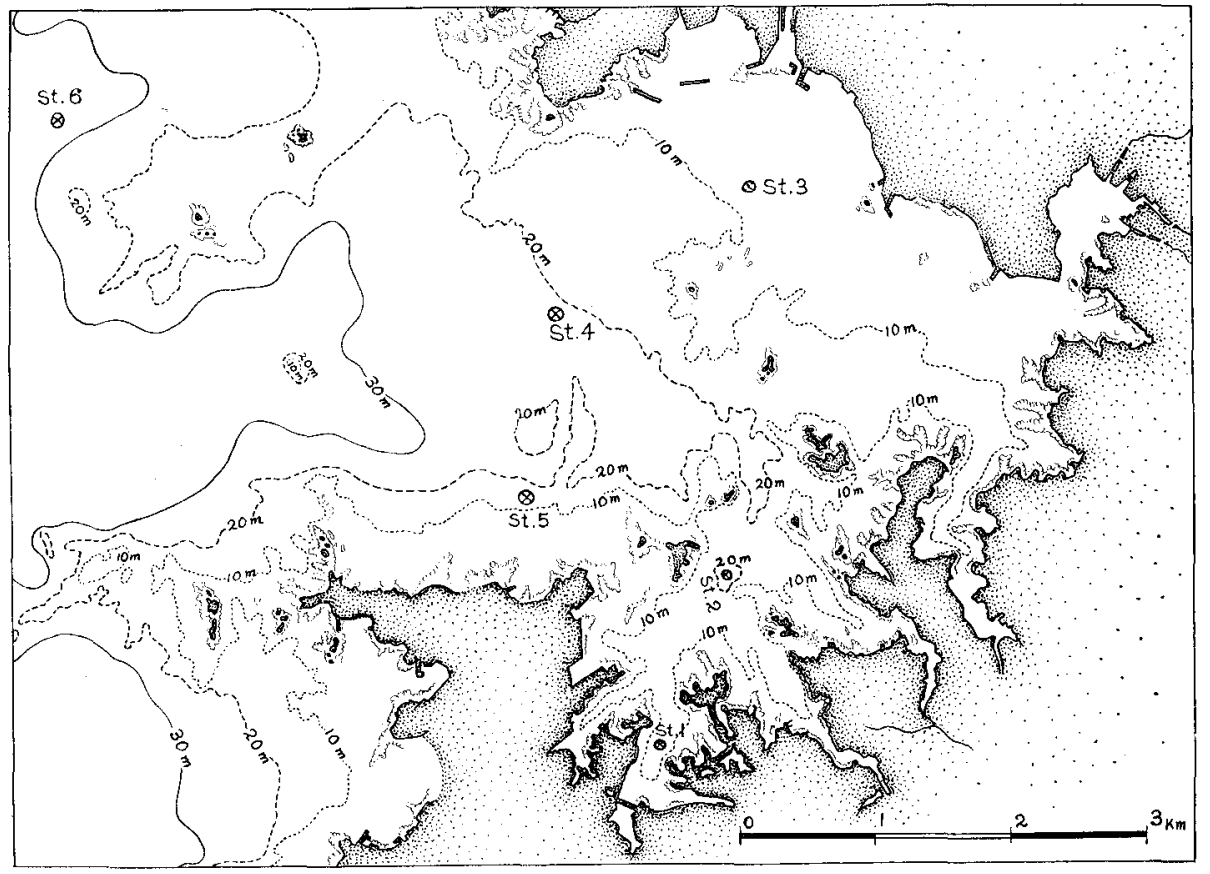

Fig. 1. Stations in Tanabe Bay.


Fig. 2. Size composition of respective samples. 
Table 1. Size composition of respective samples. Numerals indicate the number of individuals in respective samples.

\begin{tabular}{|c|c|c|c|c|c|c|c|}
\hline \multirow{2}{*}{ Station } & \multirow{2}{*}{$\begin{array}{l}\text { Hauled } \\
\text { distance }\end{array}$} & \multicolumn{7}{|c|}{ Body length in mm } \\
\cline { 2 - 7 } & & $<2$ & $2-3$ & $3-4$ & $4-5$ & $5-6$ & $6<$ \\
\hline 1 & $10-0$ & 8 & 192 & 130 & 22 & 6 & 0 \\
\hline 2 & $10-0$ & 11 & 70 & 68 & 47 & 12 & 0 \\
\hline 3 & $20-10$ & 6 & 5 & 19 & 62 & 156 & 4 \\
\hline $10-0$ & 2 & 5 & 6 & 21 & 36 & 1 \\
\hline 4 & $10-0$ & 0 & 2 & 14 & 45 & 21 & 0 \\
\hline 5 & $20-10$ & 0 & 6 & 2 & 7 & 7 & 0 \\
\hline 6 & $10-0$ & 5 & 25 & 7 & 3 & 7 & 0 \\
\hline & $10-0$ & 6 & 16 & 6 & 4 & 0 & 0 \\
\hline
\end{tabular}

Table 2. Hydrological data at respective stations.

\begin{tabular}{|c|c|c|c|c|c|c|c|}
\hline Station & Date & Time & Weather & $\begin{array}{l}\text { Depth } \\
\text { in } \\
\mathrm{m}\end{array}$ & $\begin{array}{c}\text { Water } \\
\text { temperature in } \\
\mathrm{C}\end{array}$ & $\begin{array}{l}\text { Salinity } \\
\text { in } \\
\%\end{array}$ & $\begin{array}{c}\mathrm{O}_{2} \text { in } \\
\mathrm{cc} / \mathrm{I}\end{array}$ \\
\hline \multirow{3}{*}{1} & \multirow{3}{*}{ July 24} & \multirow{3}{*}{$12: 22$} & \multirow{3}{*}{ fine } & 0 & 26.80 & 33.39 & 4.71 \\
\hline & & & & 5 & 25.62 & 33.75 & 4.48 \\
\hline & & & & 11 & 24.60 & 33.71 & 4.77 \\
\hline \multirow{5}{*}{2} & \multirow{5}{*}{ July 24} & \multirow{5}{*}{$13: 50$} & \multirow{5}{*}{ fine } & 0 & 26.95 & 33.57 & 4.67 \\
\hline & & & & 5 & 26.10 & 33.31 & 4.65 \\
\hline & & & & 10 & 25.69 & 33.48 & 3.27 \\
\hline & & & & 18 & 21.11 & 33.31 & 4.08 \\
\hline & & & & 23 & 21.95 & 34.34 & 4.50 \\
\hline \multirow{3}{*}{3} & \multirow{3}{*}{ July 24} & \multirow{3}{*}{$17: 20$} & \multirow{3}{*}{ cloudy } & 0 & 26.20 & 33.28 & 4.58 \\
\hline & & & & 5 & 26.05 & 33.30 & 4.91 \\
\hline & & & & 8 & 25.00 & 33.69 & 4.46 \\
\hline \multirow{5}{*}{4} & \multirow{5}{*}{ July 24} & \multirow{5}{*}{$\begin{array}{c}17: 52 \\
18: 20\end{array}$} & \multirow{5}{*}{ cloudy } & 0 & 25.88 & 33.31 & 4.88 \\
\hline & & & & 5 & 25.70 & 33.46 & 4.92 \\
\hline & & & & 10 & 25.35 & 33.46 & 4.85 \\
\hline & & & & 20 & 23.10 & 33.93 & 4.41 \\
\hline & & & & 24 & 22.55 & 34.14 & 4.85 \\
\hline 5 & July 26 & $7: 30$ & fine & & & & \\
\hline \multirow{4}{*}{6} & \multirow{4}{*}{ July 25} & \multirow{4}{*}{$\begin{array}{c}12: 17 \\
12: 35\end{array}$} & \multirow{4}{*}{ fine } & 0 & 26.30 & 33.53 & 4.77 \\
\hline & & & & 5 & 24.40 & & 4.76 \\
\hline & & & & 10 & 25.10 & 33.84 & 4.86 \\
\hline & & & & 30 & 26.16 & 35.01 & 4.51 \\
\hline
\end{tabular}


concentrated in the upper layer, while larger ones are accumulated in the lower layer (Station 2). The centre of reproduction of this species must be formed in the strongly sheltered and resultantly in the highly stagnant water of the bay. The development of larvae takes place in the upper layer of such areas and the animals move down to the lower layer with the growth and stay there at least in the daytime. Some parts of the population accumulated there are carried out by tidal currents. Sometimes a part of the upper layer population may flow out as seen at Sts. 5 and 6 . The populations at Sts. 3 and 4 are very small, but their composition is very noticeable in that it shows some resemblance to the composition found in the lower layer at St. 2. It is possible that the specimens collected at Stations 3 and



Fig. 3. Temperature-salinity relation diagram. The point $1-0 \mathrm{~m}$ shows the temperature and salinity in the surface layer at Station 1 and the point $3-8 \mathrm{~m}$ shows those in the $8 \mathrm{~m}$ layer at Station 3 and so on.

4 are attributable to that lower layer population, because the water of the upper layer at these stations is related more closely to the water of a considerable depth at Station 2 than to the surface water extending through Stations 1, 2, and 5, as seen clearly in the temperature-salinity relation diagram (Fig. 3). Also it is very possible that the populations at Stations 3 and 4 are attributable to the upper layer population in some other cove where the phase of reproduction might differ from that in the cove including Station $l$ and thus smaller individuals were quite scarce in the upper layer. Anyhow in such a bay as Tanabe Bay, the mixing of water must be done very confusedly because of its complicated topography and tide of a considerable scale. 
Although we are not assure of the significance of this temperature-salinity relation diagram, the diagram seems to be somewhat significant at least about the surface water above $10 \mathrm{~m}$. More samples at different layers at different stations are necessary to obtain any decisive conclusion. Unfortunately no accurate observation was made on the reproductive organs of specimens. Thus no comment can be made on the exact breeding season of this arrow worm at present, though the scarcity of individuals smaller than $2 \mathrm{~mm}$ and the rich occurrences of 2-4 $\mathrm{mm}$ long individuals in the upper layer at Sts. 1 and 2 seem to indicate that the reproduction took place in this area some time ago before July 24. Comparing the size composition of delicata-population, the hydrological data and the arrangenent of isobaths in the bay one another it seems very likely that the first of these might be availed as one of the indicators of the water movernent in the inner half of the bay.

Before closing this short note we wish to express our hearty thanks to Dr. T. Tokioka for his kind advices and to our comrades for their kindness in allowing us to cite the hydrological data they obtained. 